\title{
Analysis of Selected Technical and Technological Parameters of the Sewage Sludge Stability Process
}

\author{
Izabela Bartkowska', Dariusz Wawrentowicz' \\ 1 Bialystok University of Technology, Department of Technology and Environmental Engineering Systems, \\ ul. Wiejska 45 A, 15-351 Bialystok, Poland \\ *Corresponding author's e-mail: i.bartkowska@pb.edu.pl
}

\begin{abstract}
The article presents the results of the analysis, which was carried out in 2015-2017 on the example of autothermal installation of thermophilic sludge stabilization (ATAD) in a sewage treatment plant in Giżycko. The installation was created in 2003 as the first of its kind and still remains operational. The purpose of the conducted research was to assess the suitability of the analyzed technological parameters as tools that can be used by operators to determine the actual possibilities of changing the operating conditions of the installation or to develop an optimization strategy to reduce the energy demand. The dry mass content and organic dry mass content was used as the assessment indicators. In the analysed period, the sludge from the process contained from $47.47 \%$ to $60.80 \%$ of organic matter in the dry mass of the sludge. The organic dry matter decrease due to the process was also calculated, and it ranged from $26.4 \%$ to $48.7 \%$. The amount of sludge undergoing the process and the amount of electricity consumption were also analysed. On this basis, the energy consumption indicators in the ATAD process were calculated.
\end{abstract}

Keywords: autothermal thermophilic stabilization of sewage sludge, dry mass of sewage sludge, organic substances in sewage sludge, sewage sludge hygienization, use of sewage sludge in agriculture.

\section{INTRODUCTION}

Sewage sludge is subject to the Directive of the European Parliament and of the Council of 19 November 2008 2008/98/EC on waste (the so-called Waste Framework Directive). According to the above-mentioned directive, the sludge as a waste is subordinated to a specific hierarchy of treatment procedure. First of all, waste generation should be prevented. Furthermore, the sludge should be prepared for re-use, subjected to recycling, or other methods of recovery/recycling, and eventually rendered harmless. Prevention of sewage sludge generation is, however, not possible because it is a kind of waste that cannot be avoided. Therefore, the other priorities are important in the waste processing hierarchy, i.e. preparation for re-use or final disposal or rendering the waste completely harmless. Its re-use, however, is possible only if the sewage sludge is stabilized and sanitary-safe.

The stabilization of sewage sludge can be achieved through the use of biological, chemical or thermal methods. The biological methods are used most commonly, in particular methane fermentation and oxygen stabilization. The biological methods also include composting. However, a few designers or specialists distinguish autothermal thermophilic sludge stabilization (ATAD) among the biological methods.

There are many known methods for the stabilization and hygienization of sewage sludge. There are even more technologies based on them and devices used to implement them. Therefore, a designer faces a difficult task to choose the right one, which will allow him to obtain a product that meets the formal and legal requirements, but at the same time fulfils the expectations of investors and users. The method of final disposal of sludge may be of key importance. The most popular choice in Europe is the thermal processing of sewage sludge. However, under domestic conditions its natural use is undoubtedly the most preferred option, especially for a certain size of sewage treatment plants [Podedworna and Heidrich 2010]. The autothermal thermophilic stabilization may be an ideal solution. This process, is unfortu- 
nately still not very well-known in Poland; however, it enables to obtain organic fertilizer instead of waste in sewage treatment plants.

The research, which is the subject of this article, concerns a sewage treatment plant in which the ATAD installation has been in operation since 2003. It is a pioneer installation, which was established in Poland and has been running for the longest time. The characteristics of the ATAD installation are presented by Bartkowska [Bartkowska 2017].

The operation of devices, machines or installations is still underestimated in society. Perhaps, this is due to the fact that the concept of operation is an interdisciplinary issue. It includes the organizational, technical, ecological, economic and social issues related to the activity and operation of people and machines. In engineering terms, it can be defined as a set of activities including planning, using, servicing, diagnosing, storing and others, aiming at the safe use of installation/devices and extending the period of its/their operation. The analysis of technical and technological parameters of the implemented process can also serve this purpose.

The research, the results of which were presented in the article, was aimed at analysing the effectiveness of ATAD installations after a period of 12 years of operation. The purpose of the conducted research was to assess the suitability of the analysed technological parameters as tools that can be used by operators to determine the actual possibilities of changing the operating conditions of the installation or to develop an optimization strategy in order to reduce the energy demand. The cognitive objective of this publication is still to supplement the knowledge about the subject process as a way of acquiring the biomass that can be used as a soil conditioner. Thus, the presentation of the ATAD process as a method that effectively contributes to solving problems with the disposal of constantly increasing amounts of sewage sludge.

\section{MATERIALS AND METHODS}

The research concerned the pre-compacted sludge before the ATAD process and the sludge after the process, and which was dehydrated. The stabilized sewage sludge, according to the decision of the Minister of Agriculture and Rural Development, since 2008 has been placed on the market as an organic fertilizer.
The municipal sewage sludge processed in a two- or three-stage autothermal termophilic stabilization plant was analysed. The total residence time of sludge in the installation amounts to 8.2 full days. The capacity of ATAD installation is 90 $\mathrm{m}^{3} / \mathrm{d}$ [Bartkowska 2017]. The excessive sludge removed from the sewage line is subjected to stabilization alternatively in two places: from the recycle stream after secondary settling tanks or from the last aerated chamber of the biological reactor.

The analysis includes the results of research carried out in years 2015-2017. The sewage sludge samples for testing were collected in accordance with PN-EN ISO 5667-13: 2011. A representative sample was obtained by combining and thoroughly mixing a certain number of samples, taken at the same time from different places of the same installation, in accordance with the Regulation of the Minister of Environment of 6 February 2015 on municipal sewage sludge.

The analysis involved the dry mass content and organic substances in the concentrated and dehydrated sludge. All determinations were made in accordance with the reference test methods indicated in the Regulation of the Minister of Environment of 6 February 2015 on municipal sewage sludge.

\section{RESULTS AND DISCUSSION}

The test cycle included the analysis of the compacted sludge, which is fed to the ATAD installation. The basic parameters determining the proper operation are dry matter and organic dry matter. The results obtained during the study were subjected to a statistical analysis. Table 1 presents the numerical characteristics of the distribution of dry matter content and organic substances.

As can be seen from the data, the dry matter content in the sludge fed to the ATAD installation fluctuated within the limits of $4.37 \%$ to $6.72 \%$, and its average value was $5.38 \%$. Within the period covered by the research, an average of $77.12 \%$ of organic matter content was found in the dry mass of the sludge. The share of organic matter in the dry mass of crude sludge ranged from $73.16 \%$ to $82.48 \%$.

The proper course of the autothermal stabilization process requires the supply of sewage sludge with the appropriate dry mass content, which ensures the supply of the appropriate amount of substrates to microorganisms, owing to which the distribution of organic substances 
Table 1. Numerical characteristics of the analysed distributions of dry mass content $(\%)$ and organic substances (\%) in compacted sludge

\begin{tabular}{|l|c|c|}
\hline \multirow{2}{*}{ Distribution measure } & \multicolumn{2}{|c|}{$\begin{array}{c}\text { The values of the distribution } \\
\text { measures }\end{array}$} \\
\cline { 2 - 3 } & dry mass & $\begin{array}{c}\text { of organic } \\
\text { substances }\end{array}$ \\
\hline Amount & 238 & 238 \\
\hline Arithmetic mean & 5.38 & 77.12 \\
\hline Maximum & 6.72 & 82.48 \\
\hline Minimum & 4.37 & 73.16 \\
\hline Median & 5.34 & 77.06 \\
\hline Variance & 0.211 & 2.787 \\
\hline Standard deviation & 0.459 & 1.669 \\
\hline Percentile 10\% & 4.82 & 75.00 \\
\hline Percentile 90\% & 6.03 & 79.23 \\
\hline
\end{tabular}

is possible, provided the process is supplied with the proper amount of oxygen. The initial sludge concentration should reach the value of up to $5 \%$ of dry mass, resulting in a higher unit organic content, which should be from $65 \%$ to $70 \%$ of dry mass and should not be lesser than $40.0 \mathrm{~g} / \mathrm{l}$, expressed in COD. In the studied period, however, the ATAD installation operation regime ensured even higher values.

In the initial period of operation of this installation (in years 2003-2005), the dry mass content in the compacted sludge ranged from $2.1 \%$ to $8.4 \%$, whereas organic substances constituted $70.05 \%$ to $86.16 \%$ of the entire volume [Bartkowska and Wawrentowicz 2011].

In other wastewater treatment plants that operate the ATAD installation, the dry mass content in compacted sludge ranged from $3.4 \%$ to $5.8 \%$, $1.1 \%$ to $8.5 \%$ and from $2.28 \%$ to $8.46 \%$. The organic matter content in the dry mass of this sludge was $35.5-74.3 \%$, respectively and $35.51-73.78 \%$ [Bartkowska 2017].

In the study cycle presented in this paper, the content of dry mass and organic substances in the sludge after the ATAD process and dehydration was also controlled. The obtained results were subjected to a statistical analysis. Table 2 presents the numerical characteristics of the distribution of dry mass content and organic substances.

The sludge generated within the period under analysis contained from $15.08 \%$ to $24.38 \%$ of dry mass, on average $19.15 \%$. The organic substance content was on average $57.13 \%$ and ranged from $47.47 \%$ to $60.80 \%$.

In the initial period of operation of this installation, the content of organic matter in the dry mass of the sludge ranged from $63.2 \%$ to $68.8 \%$.
In the next cycle of tests, the organic matter content in the dry mass of sewage sludge after the ATAD process and dehydration was on average 62.1\% [Bartkowska and Dzienis 2007].

In other wastewater treatment plants in the country that operate the ATAD plant, the content of organic substances in the treated sewage sludge varies from $30 \%$ to $60 \%$ in the dry mass of the sludge.

In Poland, there is no legally regulated concept of stabilized sewage sludge. However, according to the German guidelines, the sludge, which contains $55 \%$ to $60 \%$ of organic matter in its dry mass, is known as the stabilized sludge. With regard to technical devices, the degree of sludge mineralization can be determined using the percentage loss of dry organic matter. The more so, because there is the concept of the socalled technical limit of stabilization, which is assumed at the level of $38-40 \%$ reduction of initial organic dry mass [Borowski and Szopa 2007, Movahedian et al. 2005].

On the basis of the analysed research results, the percentage decrease of organic matter content in the dry mass of sludge was calculated. During the period of research, it ranged from $26.4 \%$ to $48.7 \%$. Similar values were obtained in other studies. For example, the reduction of organic matter content in the dry mass in the sludge recorded in Ireland was from $28.5 \%$ to even 53.8\% [Layden 2007]. The loss of organic matter in the dry mass of sludge, according to the research by Zhelev et al. [2008], was $25 \div 56 \%$. In other sources, the content of organic substances dropped within $32 \div 51 \%$ [Zupančič and Roš 2008 , Song and $\mathrm{Hu} 2005]$. In subsequent studies with an

Table 2. Numerical characteristics of the analysed distributions of dry mass content (\%) and organic substances $(\%)$ in the compacted sludge

\begin{tabular}{|l|c|c|}
\hline \multirow{2}{*}{ Distribution measure } & \multicolumn{2}{|c|}{$\begin{array}{c}\text { The values of the distribution } \\
\text { measures }\end{array}$} \\
\cline { 2 - 3 } & dry mass & $\begin{array}{c}\text { of organic } \\
\text { substances }\end{array}$ \\
\hline Amount & 238 & 238 \\
\hline Arithmetic mean & 19.15 & 57.13 \\
\hline Maximum & 24.38 & 60.80 \\
\hline Minimum & 15.08 & 47.47 \\
\hline Median & 19.34 & 57.11 \\
\hline Variance & 3.107 & 6.814 \\
\hline Standard deviation & 1.762 & 2.610 \\
\hline Percentile 10\% & 16.84 & 53.86 \\
\hline Percentile 90\% & 21.14 & 60.46 \\
\hline
\end{tabular}


extended retention time of up to 23 days, the average organic content dropped by $45 \%$ [Shugen et al. 2012]. While conducting tests at the time of sludge retention similar to the technical conditions (6-10 days), the organic matter content was not higher than 33.2\% [Shugen et al 2013]. The quoted results are the result of the research carried out at a laboratory scale in a single reactor.

The summary of the amount of sludge brought to the ATAD installation was analyzed as well. In the analysed period, the monthly processing ranged from $1175 \mathrm{~m}^{3}$ to $3644 \mathrm{~m}^{3}$. A detailed summary of the amount of sludge is shown in Figure 1.

The sludge is supplied for ATAD installation once per day. In the period under study, this average quantity was $84.54 \mathrm{~m}^{3} / \mathrm{d}$; however, it changed from the minimum value of $37.90 \mathrm{~m}^{3} / \mathrm{d}$ to the maximum value of $117.55 \mathrm{~m}^{3} / \mathrm{d}$. The total amount of sludge that underwent the ATAD process was $87,518,60 \mathrm{~m}^{3}$. This sludge was completely used for agricultural purposes as an organic fertilizer after dehydration.

The thermophilic population of microorganisms is characterized by a high rate of oxygen absorption The process requires constant aeration of sludge and mixing in the reactors. This is associated with a marked increase in the energy consumption. Figure 2 shows the energy consumption in ATAD reactors.

In the studied period, the average amount of energy consumed was $61,186.79 \mathrm{kWh}$ in a month. The least energy was used in April 2016 and it was 47,640.00 kWh, and the most in October 2016, when it was $78,780 \mathrm{kWh}$. In the analysed period, the lower consumption of electricity fell on the months from March to July each year. However,

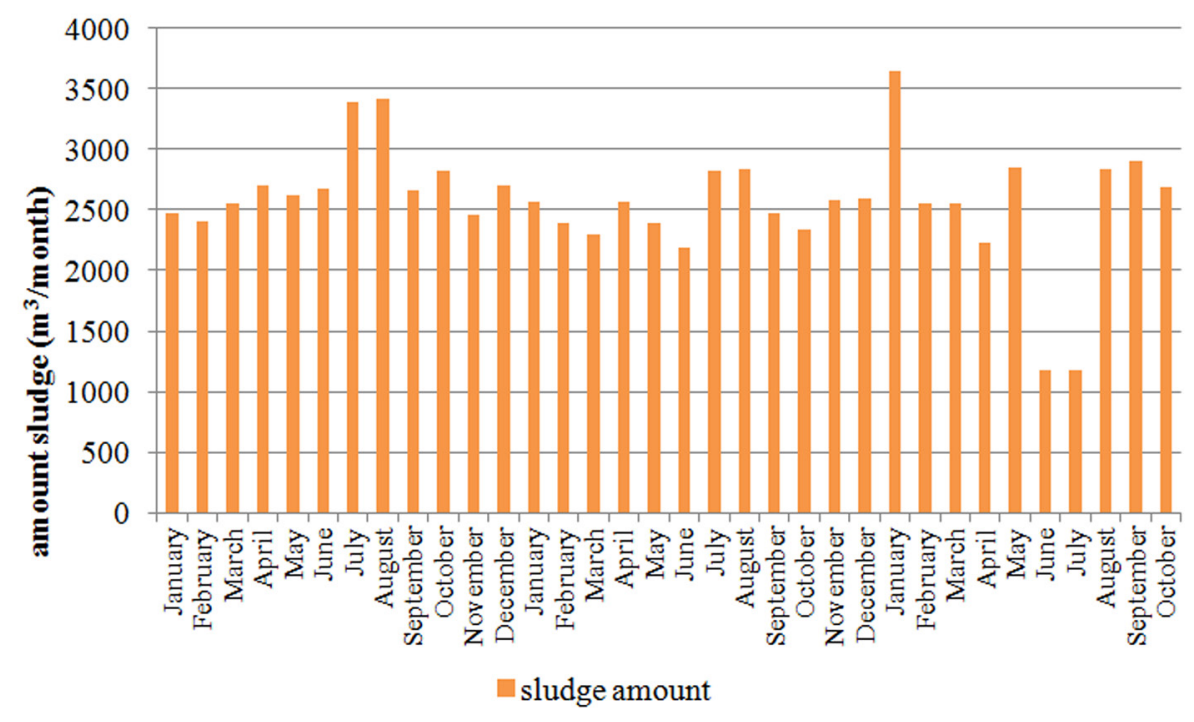

Fig. 1 Monthly quantities of sludge processed from January 2015 to October 2017

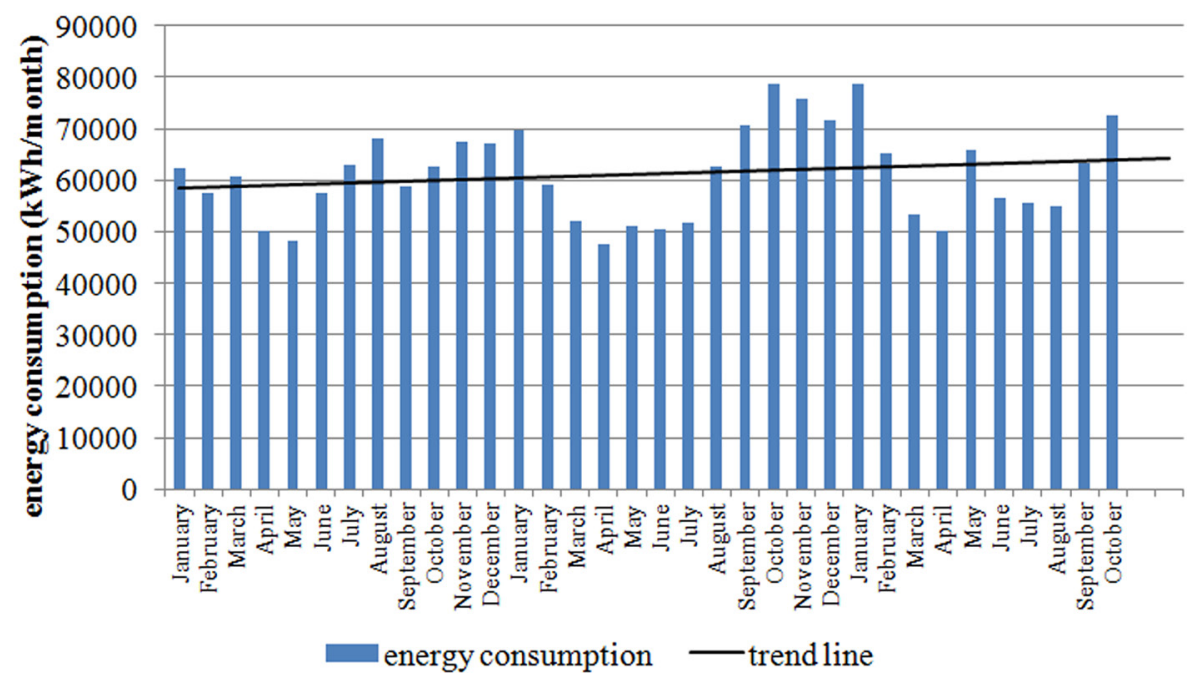

Fig. 2. Monthly values of energy consumption in the ATAD installation from January 2015 to October 2017 
the trend line shown in the picture clearly indicates a growing energy consumption.

The knowledge on the energy balance of a sewage treatment plant allows to assess the energy consumption of individual processes using technical indicators that specify the amount of electricity consumption. Taking into account the monthly energy consumption, volume and mass of the generated sludge and the energy consumption indicators were calculated. The values of the calculated ratios are presented in Table 3 .

Acquiring information on energy consumption for selected processes in a sewage treatment plant is relatively difficult. The existing metering usually allows to determine the total energy consumption. In certain wastewater treatment plants, however, it is possible to record the energy consumption for individual processes or devices. In other waste-water treatment plants in the country with the the sludge management based on the ATAD process, the calculated energy consumption rates were $13.3 \mathrm{kWh} / \mathrm{m}^{3}$ for the processed sludge, and in relation to $1 \mathrm{~kg}$ of dry matter of sludge $0.44 \mathrm{kWh} / \mathrm{kg}$ of dry mass. The research carried out in the next sewage treatment plant enabled to calculate the energy consumption indicators in the years 2013-2015 in the range from $23.26 \mathrm{kWh} / \mathrm{m}^{3}$ to $33.32 \mathrm{kWh} / \mathrm{m}^{3}$. However, per kilogram of dry matter from $0.23 \mathrm{kWh} / \mathrm{kg}$ of dry mass to $0.28 \mathrm{kWh} / \mathrm{kg}$ of dry mass was achieved in the same period of time [Bartkowska 2017].

Rojas et al. [2010] state that the energy consumption indicators in ATAD installations operating in Spain and Ireland are $9-15 \mathrm{kWh} / \mathrm{m}^{3}$ of processed sludge or $0.3-0.5 \mathrm{kWh} / \mathrm{kg}$ of dry mass. This means that under domestic conditions, the energy consumption with respect to 1 $\mathrm{m}^{3}$ of processed sludge is higher, and in relation to one kilogram of dry matter it is lower or takes the lower values from the given range. Therefore, our installations can be considered more energyconsuming, since the expression of the amount of sludge in $1 \mathrm{~m}^{3}$ is unambiguous. However, the approach to assuming the amount of sludge in kilograms of dry matter, is clearly different. Skilful operation can also affect the energy balance.
Unfortunately, there is little information on the energy consumption of the ATAD process in the scientific literature, apart from the remarksthat it is significant.

Other technologies of sludge stabilization also contribute to the increase of energy consumption in sewage treatment plants. On the basis of the energy consumption in the treatment plant for the process of oxygen stabilization of sludge, the discussed indicators range from 6.44 $\mathrm{kWh} / \mathrm{m}^{3}$ to $13.25 \mathrm{kWh} / \mathrm{m}^{3}$ and from $2.96 \mathrm{kWh} /$ $\mathrm{kg}$ of dry mass to $6.02 \mathrm{kWh} / \mathrm{kg}$ of dry mass [Dąbrowski et al. 2017].

\section{CONCLUSIONS}

The research conducted in the existing ATAD installations confirmed the effectiveness of this process in acquiring stabilized sewage sludge and it being safe in terms of hygiene and sanitation. The process enables to obtain sludge that does not rot and is devoid of pathogenic microorganisms, parasites and fungi. The ATAD installation requires a small area, and the process is carried out in closed tanks.

The results discussed in the article refer to the installation that has been in operation since 2003 . Almost a 15 -year operation period allows to realistically assess the advantages and disadvantages of this technology.

From the practical point of view, the analysis of the degree of stabilization of the sludge should be made using the methods which are simple to conduct and possible on-site at the sewage treatment plant. This gives the opportunity to react quickly and achieve greater efficiency of the installation. For this reason, the study has focused on the content of dry matter and organic substances. These two technological parameters determine the effectiveness of the process. As a measure of effectiveness, it is necessary to indicate the decrease in organic matter content in the dry mass of the sludge.

Exploitation of the installation is a set of purposeful organizational, technical and economic

Table 3. The values of energy consumption indicators in the ATAD installation in 2015-2017

\begin{tabular}{|c|c|c|c|}
\hline \multirow{2}{*}{ Indicator } & \multicolumn{3}{|c|}{ Energy consumption indicator } \\
\hline & mean & minimal value & maximal value \\
\hline Energy consumption index for $1 \mathrm{~m}^{3}$ of processed sludge $\left(\mathrm{kWh} / \mathrm{m}^{3}\right)$ & 24.72 & 18.34 & 48.00 \\
\hline $\begin{array}{l}\text { Energy consumption indicator for } 1 \mathrm{~kg} \text { of dry matter of sludge (kWh } \\
/ \mathrm{kg} \text { of dry mass) }\end{array}$ & 0.13 & 0.09 & 0.24 \\
\hline
\end{tabular}


activities of people concerning their technical object and mutual relations occurring between them from the moment the object is commisioned for use in accordance with the intended purpose, up to the time of liquidation. The length of this period can be extended following certain rules most often given by the manufacturer.

The dry mass content constitutes a very important technological parameter of the sludge. The thickening of sludge to the required value of 4-5\% ensures the supply of an appropriate amount of substrates to microorganisms, owing to which the distribution of organic substances is possible, provided, however, the right amount of oxygen is supplied. Maintaining the dry mass content at this level in the sludge supplied to the first level reactor will help avoid many operational problems. Higher content of dry mass may cause a faster wear of moving parts of aeration and mixing devices or foam controllers. It can also cause an increased energy consumption, which can be seen on the example of the installation. It was found that only in $20 \%$ of the analysed test results, the dry mass content was up to $5 \%$. During the research period, the dry mass content averaged at $5.38 \%$. Additionally, the amount of sludge supplied once to the installation often exceeded the designed value $\left(90 \mathrm{~m}^{3} / \mathrm{d}\right)$.

Examination of the dry mass content and its organic fraction before and after the process allows to determine the loss of organic matter content in the sludge, which can be a measure of the degree of its stabilization. As can be seen, the installation still ensures that this condition is met.

Of course, one should not forget about the temperature control of the sludge in the reactors, as the temperature of the thermophilic process guarantees the sanitation of the sludge. Achieving this temperature is possible, among other things, owing to the corresponding content of organic substances in the dry mass of the sludge.

\section{Acknowledgement}

The analyzes were carried out as part of the work No S/WBiIŚ /02/2014 and financed from the funds of the Ministry of Science and Higher Education.

\section{REFERENCES}

1. Bartkowska I. 2017. Autothermal thermophilic aerobic digestion of sewage sludge. Wydawnictwo Seidel-Przywecki Sp. z o. o., Warszawa (in Polish).
2. Bartkowska I., Dzienis L. 2007. Technical and economic aspects of autothermal thermophilic aerobic digestion exemplified by sewage treatment plant in Giżycko. Environment Protection Engineering, 33(2), 17-25.

3. Bartkowska I., Wawrentowicz D. 2011. Efficiency analysis of sewage sludge treatment by means of autoheated thermophilic aerobic digestion (ATAD) on the example of wastewater treatment plant in Giżycko. Inżynieria Ekologiczna, 25, 165-175 (in Polish).

4. Borowski S., Szopa J. 2007. Experiences with the dual digestion of municipal sewage sludge, Bioresource Technology, 98, 1199-1207.

5. Dąbrowski W., Żyłka R., Malinowski P. 2017. Evaluation of energy consumption during aerobic sewage sludge treatment in dairy wastewater treatment plant. Environmental Research, 153, 135-139.

6. Layden N.M. 2007. An evaluation of autothermal thermophilic aerobic digestion (ATAD) of municipal sludge in Ireland. Journal of Environmental Engineering and Science, 6, 19-29.

7. Movahedian A.H., Bina B., Moeinian K. 2005. Effects of aeration rate and detention time on thermophilic aerobic digestion of mixed sludge and its dewaterability. International Journal of Environmental Science and Technology, 2(2), 105-111.

8. Podedworna J., Heidrich Z. 2010. Directions of final disposal of sewage sludge. Gaz, Woda i Technika Sanitarna, 3, 25-28 (in Polish).

9. Rojas J., Zhelev T., Graells M. 2010. Energy Efficiency Optimization of Wastewater Treatment Study of ATAD. Computer Aided Chemical Engineering, 28, 967-972.

10. Shugen L., Nanwen Z., Ping N., Xudong G. 2012. The one-stage autothermal thermophilic aerobic digestion for sewage sludge treatment: Effects of temperature on stabilization process and sludge properties. The Chemical Engineering Journal, 197, 223-230.

11. Shugen L., Nanwen Z., Ping N., Xudong G. 2013. Semicontinuous Operation of One-Stage Autothermal Thermophilic Aerobic Digestion of Sewage Sludge: Effects of Retention Time. Journal of Environmental Engineering, 139(3), 422-427.

12. Song Yu-dong, Hu Hong-ying 2005. Autothermal Thermophilic Aerobic Digestion Technology for Sewage Sludge Treatment. China Water \& Wastewater, 27(6).

13. Zhelev T., Jamniczky-Kaszas D., Brzyszcz B., Trévarain M., Kovacs R Vaklieva-Bancheva N. 2008. Energy efficiency improvement of waste-water treatment processes using process integration techniques. Report prepared for the Environmental Protection Agency by University of Limerick.

14. Zupančič G.D., Roš M. 2008. Aerobic and twostage anaerobic-aerobic sludge digestion with pure oxygen and air aeration. Bioresource Technology, 99, 100-109. 